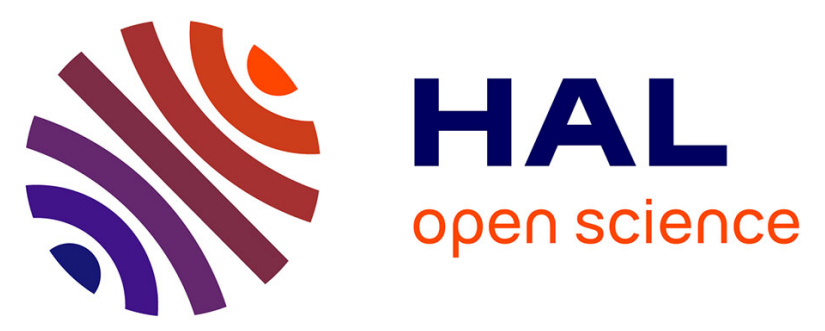

\title{
Crystallographic analysis shows substrate binding at the -3 to +1 active site subsites and at the surface of glycoside hydrolase family 11 endo-1,4-beta-xylanases
}

Elien Vandermarliere, Tine M. Bourgois, Sigrid Rombouts, Steven van Campenhout, Guido Volckaert, Sergei V. Strelkov, Jan A. Delcour, Anja Rabijns, Christophe M. Courtin

\section{To cite this version:}

Elien Vandermarliere, Tine M. Bourgois, Sigrid Rombouts, Steven van Campenhout, Guido Volckaert, et al.. Crystallographic analysis shows substrate binding at the -3 to +1 active site subsites and at the surface of glycoside hydrolase family 11 endo-1,4-beta-xylanases. Biochemical Journal, 2008, 410 (1), pp.71-79. 10.1042/BJ20071128 . hal-00478874

\section{HAL Id: hal-00478874 https://hal.science/hal-00478874}

Submitted on 30 Apr 2010

HAL is a multi-disciplinary open access archive for the deposit and dissemination of scientific research documents, whether they are published or not. The documents may come from teaching and research institutions in France or abroad, or from public or private research centers.
L'archive ouverte pluridisciplinaire HAL, est destinée au dépôt et à la diffusion de documents scientifiques de niveau recherche, publiés ou non, émanant des établissements d'enseignement et de recherche français ou étrangers, des laboratoires publics ou privés. 
Crystallographic analysis shows substrate binding at the -3 to +1 active site subsites and at the surface of glycoside hydrolase family 11 endo-1,4- $\beta$-xylanases.

Elien Vandermarliere ${ }^{*}$, Tine M. Bourgois ${ }^{\dagger}$, Sigrid Rombouts ${ }^{\dagger}$, Steven Van Campenhout ${ }^{\dagger}$, Guido Volckaert ${ }^{\dagger}$, Sergei V. Strelkov ${ }^{*}$, Jan A. Delcour ${ }^{\dagger}$, Anja Rabijns ${ }^{*}$, Christophe M. Courtin

* Laboratory for Biocrystallography, Department of Pharmaceutical Sciences, Katholieke Universiteit Leuven, Herestraat 49, O\&N II, bus 822, 3000 Leuven, Belgium

${ }^{\dagger}$ Laboratory of Gene Technology, Department of Biosystems, Katholieke Universiteit Leuven, Kasteelpark Arenberg 21, bus 2462, 3001 Leuven, Belgium

$\$$ Laboratory of Food Chemistry and Biochemistry, Department of Molecular and Microbial Systems, Katholieke Universiteit Leuven, Kasteelpark Arenberg 20, bus 2463, 3001 Leuven, Belgium.

Corresponding author: Elien Vandermarliere

Laboratory for Biocrystallography, Department of Pharmaceutical Sciences, Katholieke Universiteit Leuven, Herestraat 49, O\&N II, bus 822, 3000 Leuven, Belgium Tel: +32(0)16323427, Fax: +32(0)16323469, e-mail: Elien.Vandermarliere@pharm.kuleuven.be

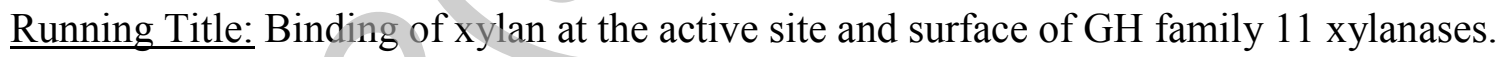




\section{Synopsis}

Glycoside hydrolase family 11 xylanases are predominant enzymes in the hydrolysis of heteroxylan, an abundant structural polysaccharide in the plant cell wall. To gain more insight in the protein-ligand interactions of the glycon as well as the aglycon subsites of these enzymes, catalytically incompetent mutants of Bacillus subtilis and Aspergillus niger xylanases were crystallized, soaked with xylo-oligosaccharides and subjected to Xray analysis. For both xylanases, there was clear density for xylose residues in the -1 and -2 subsites. In addition, for the B. subtilis xylanase, there was also density for xylose residues in the -3 and +1 subsite showing the spanning of the $-1 /+1$ subsites. These results together with the observation that some residues in the aglycon subsites clearly adopt a different conformation upon substrate binding allowed us to identify the residues important for substrate binding in the aglycon subsites. In addition to substrate binding in the active site of the enzymes, the existence of an unproductive second ligand binding site located on the surface of both the B. subtilis and $A$. niger xylanases was observed. This extra binding site may have a function similar to the separate carbohydrate binding modules of other glycoside hydrolase families.

Key words: Family 11 glycoside hydrolases, Bacillus subtilis xylanase, Aspergillus niger xylanase, inactive mutant, substrate binding subsites, surface binding 


\section{Introduction}

Heteroxylan is a polysaccharide found in the plant cell wall, especially in the secondary wall where it is the major noncellulosic polysaccharide [1]. It is composed of a homopolymeric linear backbone of $\beta$-1,4-linked D-xylopyranosyl units which can be

substituted with L-arabinofuranosyl, acetyl, glucuronic, 4-O-methylglucuronic and/or pcoumaric residues depending on its source [2]. A consequence of this diversity is the need for a large variety of cooperatively acting enzymes to achieve complete hydrolysis of heteroxylan. These can be found both in the plant where they play a role in seed germination and in fungi and bacteria where they initialize a pathogenic attack. Hydrolysis of the xylan backbone is performed mainly by endo- $1,4-\beta$-xylanases (EC 3.2.1.8, xylanases). Most xylanases can be found in glycoside hydrolase families 10 and 11 (GH 10 and 11), a classification based on amino acid sequence homology of the catalytic domains [3].

GH 10 xylanases have a $(\beta / \alpha)_{8}$ barrel as catalytic domain and typically contain one or more carbohydrate binding domains which increase the effective concentration of the active site on polymeric substrates [4]. The structure of GH 11 xylanases has been described as a partially closed right hand. It consists of only one domain folding into two $\beta$-sheets which are packed against each other, and one $\alpha$-helix. The two $\beta$-sheets are strongly twisted and form a cleft on one side of the protein in which the active site is situated. This cleft is covered by a long loop region which is called the thumb region and partly closed on one side by the cord, a long irregular loop with a well-defined structure [5]. In contrast to GH 10 xylanases, no carbohydrate binding modules are present. A consequence of the difference in structure is their difference in substrate specificity. The active site of GH 10 xylanases is a shallow groove which is reflected in their specificity towards a lower number of unsubstituted consecutive xylose units. In contrast, GH 11 xylanases show higher affinity towards a larger number of unsubstituted consecutive xylose units because of their cleft-shaped active site [6]. Not only between but also within each family, there are differences in substrate specificity $[7,8]$.

The reaction mechanism of both $\mathrm{GH} 10$ and 11 xylanases is a general acid-base mechanism resulting in retention of the anomeric configuration in the product. It involves two acidic amino acid residues, one acting as an acid/base and one as a nucleophile. For 
xylanases of GH families 10 and 11, these two catalytic residues are glutamic acids [9, $10]$.

The active site of GH 11 xylanases contains many aromatic residues which are important for substrate binding. They can make hydrophobic stacking interactions with the sugar residues and their hydroxyl groups can form hydrogen bonds [11]. Using the substrate binding subsite nomenclature proposed by Davies and co-workers, the subsites are labeled from $-\mathrm{n}$ to $+\mathrm{n}$, where $-\mathrm{n}$ are the glycon subsites and $+\mathrm{n}$ the aglycon subsites. Hydrolysis takes place between the -1 and +1 subsites [12]. For GH 11 xylanases, the glycon subsites have been crystallographically characterized for Bacillus circulans xylanase [13-15], Trichoderma reesei xylanase II [16], Bacillus agaradhaerens xylanase $[17,18]$ and Chaetomium thermophilum xylanase [19]. Especially the -1 and -2 subsites have been well characterized. In contrast, to date, the characterization of the aglycon subsites was only based on modeling [20, 21]. Also, no structural information on sugars spanning the -1 and +1 subsites is available. This is due to the fact that, in native xylanase, any bound xylan chain is immediately hydrolysed and the aglycon part lost due to the low affinity of the aglycon binding subsites.

Hence, to explore the aglycon subsites and gain more insight in the substrate specificity of different GH 11 xylanases, we followed the strategy used by Wakarchuk and coworkers to produce an inactive mutant [15]. The mutation of the acid/base glutamate to an alanine prevents the first step in the reaction mechanism resulting in the inactivation of the xylanase without distortion of the substrate conformation. In this study, we have substituted both the acid/base glutamate of Bacillus subtilis xylanase, E172, and that of Aspergillus niger xylanase (accession number P55328), E170, to an alanine. This gives us an example of both an alkaline (B. subtilis) and an acidophilic (A. niger) xylanase [22]. Crystals of these inactive xylanases were soaked with xylo-oligosaccharides and the structures of the complexes were solved by X-ray crystallography, providing insight into the substrate binding of xylanases at both the glycon and aglycon subsites. Interestingly, we found a second, unproductive ligand binding site located on the surface of both xylanases, possibly providing a hint towards explaining the difference in activity and/or functionality between different xylanases. 


\section{Experimental}

\section{Materials}

Oligonucleotide primers were purchased from Proligo Primers and Probes (Paris, France). Restriction enzymes were from Roche Diagnostics GmbH (Mannheim, Germany) and $P f u$ DNA polymerase for polymerase chain reaction (PCR) was from Fermentas GmbH (St. Leon-Rot, Germany). Escherichia coli strain TOP10F' from Invitrogen (Carlsbad, CA, USA) was used for transformation of DNA constructs, except in case of the pCR $4{ }^{\circledR}-\mathrm{TOPO}^{\circledR}$ vector from Invitrogen, for which $E$. coli TOP10 from Invitrogen was used. E. coli WK6 was used as host strain for heterologous expression with expression vector pQE-Ec [23]. Expression in Pichia pastoris was performed with expression vector $\mathrm{pPICZ} \alpha \mathrm{C}$ (Invitrogen) containing the $\alpha$-factor signal sequence from Saccharomyces cerevisiae to direct the expressed protein to the medium. The Easy Select Pichia Expression kit (Invitrogen) was used for transformation of competent P. pastoris X33 cells.

\section{Construction of the inactive mutants}

For B. subtilis xylanase, the E172A mutant was generated using the megaprimer method [24] with pQE-En-XynA as a template [25]. In case of A. niger xylanase, a pCR $4^{\circledR}$ TOPO $^{\circledR}$ vector containing the $A$. niger xylanase gene (accession number P55328) was used as a template in a new PCR reaction with primers AnExf02 and AnExr02 to remove a remaining part of the signal sequence. The megaprimer was amplified using the forward primers BsXynAf02 and AnExf02 for B. subtilis and A. niger respectively together with reverse primers containing the mutation (BsE172Ar for B. subtilis and AnE170Ar for $A$. niger) (Table 1). Amplification of the megaprimer product was obtained by 35 cycles of 1 min at $95^{\circ} \mathrm{C}, 90 \mathrm{sec}$ at $58^{\circ} \mathrm{C}, 2 \mathrm{~min}$ at $72^{\circ} \mathrm{C}$ and 1 cycle of $15 \mathrm{~min}$ at $72^{\circ} \mathrm{C}$. The PCR products were gel-extracted (QIAquick gel extraction kit, Qiagen GmbH, Hilden, Germany), purified (MSB Spin PCRapace kit, Invitek GmbH, Berlin, Germany) and used as a megaprimer in a subsequent PCR reaction to complete the coding sequence. For the final PCR reaction, conditions were used as described in Smith and Klugman [24]. Briefly, $2 \mu \mathrm{g}$ of megaprimer product was used with $2 \mathrm{ng}$ of template and $1 \mu \mathrm{M}$ of the flanking primer containing a stop codon: BsXynAr03 and AnExrstop for B. subtilis 
xylanase and $A$. niger xylanase respectively. The latter primer was added after 5 cycles of denaturation at $95^{\circ} \mathrm{C}$ for $1 \mathrm{~min}$ and extension at $72^{\circ} \mathrm{C}$ for $3 \mathrm{~min}$. The remaining 35 cycles of the PCR program were $1 \mathrm{~min}$ at $95^{\circ} \mathrm{C}, 90 \mathrm{sec}$ at $52^{\circ} \mathrm{C}, 2 \mathrm{~min}$ at $72^{\circ} \mathrm{C}$ and 1 cycle of 15 min at $72^{\circ} \mathrm{C}$. The resulting product was cloned in a pCR $4^{\circledR}-\mathrm{TOPO}^{\circledR}$ vector after gel purification (Qiagen) and addition of 3' A-overhangs with SuperTaq polymerase (SphaeroQ, Leiden, The Netherlands) (2.5 Units, $\left.72^{\circ} \mathrm{C}, 10 \mathrm{~min}\right)$. The presence of the mutation and the absence of other mutations were verified by DNA sequencing and the mutant B. subtilis xylanase gene (E172A) was subcloned in the BgllI site of the pQE-Ec vector whereas the mutant $A$. niger xylanase gene (E170A) was subcloned as a $B g l I I$ fragment in the $B s m \mathrm{BI}$ site of the $\mathrm{pPICZ} \alpha \mathrm{C}$ vector. The ligation mixture was used to transform E. coli TOP10F' cells. A sequence verified pPICZ $\alpha \mathrm{C}$ E170A construct, linearized with PmeI, was used to transform competent P. pastoris X33 cells according to the instructions from the manufacturer. All primers used are further characterized in Table 1.

\section{Recombinant expression of the $B$. subtilis E172A xylanase mutant}

Protein expression of the E172A xylanase mutant was performed in transformed E. coli WK6 cells according to instructions of the QIAexpress expression system (Qiagen). Cultures were grown in Luria-Bertani medium supplemented with $100 \mu \mathrm{g} \mathrm{ml}^{-1}$ ampicillin and $2 \% \mathrm{D}(+)$-glucose $\left(37^{\circ} \mathrm{C}\right.$, shaking at $\left.225 \mathrm{rpm}\right)$ until the absorbance at $600 \mathrm{~nm}$ reached approximately 0.5 . Expression was induced with $0.2 \mathrm{mM}$ isopropyl- $\beta$-Dthiogalactopyranoside for $16 \mathrm{~h}$ at $16^{\circ} \mathrm{C}$. Lysate was prepared according to the manufacturer's instructions (Qiagen). To improve protein yield, 3 cycles of freezethawing $\left(-80^{\circ} \mathrm{C}\right.$ to $\left.25^{\circ} \mathrm{C}\right)$ were included. Protease inhibitor Pefablock SC (VWR International) was added to a final concentration of $1 \mathrm{mM}$.

The purification of the E172A mutant was carried out in two chromatographic steps. The obtained lysate was dialysed overnight at $4{ }^{\circ} \mathrm{C}$ against $25 \mathrm{mM}$ sodium acetate buffer $(\mathrm{pH}$ 5.0) and then concentrated on a SP-Sepharose Fast Flow column (GE Healthcare Life Science, Uppsala, Sweden) equilibrated with the same buffer. Bound proteins were eluted using a linear salt gradient of 0 to $1.0 \mathrm{M}$ sodium chloride. Protein fractions containing E172A were pooled, desalted and dialysed against $25 \mathrm{mM}$ sodium acetate buffer ( $\mathrm{pH} 5.0$ ) 
containing 0.2 M sodium chloride. The sample was then loaded on the Triticum aestivum xylanase inhibitor affinity column. Bound proteins were eluted with $0.25 \mathrm{M}$ Trishydrogen chloride ( $\mathrm{pH}$ 12.0). The eluate was neutralised immediately with $1.0 \mathrm{M}$ acetic acid and dialysed against $25 \mathrm{mM}$ sodium acetate buffer $(\mathrm{pH}$ 5.0). After each purification step, protein purity was verified by sodium dodecyl sulphate-polyacrylamide gel electrophoresis.

\section{Recombinant expression of the $A$. niger E170A xylanase mutant}

A single $P$. pastoris $\mathrm{X} 33$ colony harbouring the E170A encoding gene was used to inoculate buffered minimal glycerol-complex medium $(\mathrm{pH} 6.0)(10 \mathrm{ml})$ containing 0.35 $\mathrm{M}$ sodium chloride and incubated for $24 \mathrm{~h}\left(30^{\circ} \mathrm{C}\right.$, shaking at $\left.250 \mathrm{rpm}\right)$. The volume was increased to $500 \mathrm{ml}$ in a 21 flask and incubated overnight $\left(30^{\circ} \mathrm{C}\right.$, shaking at $\left.250 \mathrm{rpm}\right)$. A preinduction transition phase was included whereby $1: 10$ volume of $10 \%(\mathrm{v} / \mathrm{v})$ glycerol / $13.4 \%(\mathrm{w} / \mathrm{v})$ yeast nitrogen base was added to the primary culture. The resulting mixture was incubated for an additional 3-5h until the number of cells $\mathrm{ml}^{-1}$ reached $0.4 \times 10^{9}$ to $0.6 \times 10^{9}$. The cell culture was harvested by centrifugation $(2500 \mathrm{~g}, 10 \mathrm{~min})$. To induce protein expression, the cells were suspended in a buffered minimal methanol-complex medium ( $\mathrm{pH} 6.0$ ) to $2.5 \times 10^{9}$ cells $\mathrm{ml}^{-1}$ and $1 \%(\mathrm{v} / \mathrm{v})$ methanol was added every 24 hours. The induction was performed in baffled flasks during $73 \mathrm{~h}$ with vigorous shaking $\left(20^{\circ} \mathrm{C}, 250 \mathrm{rpm}\right)$. The cultures were harvested by centrifugation $(2500 \mathrm{~g}, 10 \mathrm{~min})$.

The recombinant protein containing supernatant was dialysed overnight against $0.25 \mathrm{M}$ Tris-hydrogen chloride buffer $(\mathrm{pH} \mathrm{8.5)}$ prior to purification. The mutant protein was purified with anion exchange chromatography using a Q-Sepharose Fast Flow column equilibrated with the same buffer. Bound proteins were eluted using a linear salt gradient of 0 to $1.0 \mathrm{M}$ sodium chloride. The protein was then dialysed against $25 \mathrm{mM}$ sodium acetate buffer ( $\mathrm{pH}$ 5.0).

\section{Crystallization and soaking experiments}

Both B. subtilis and A. niger inactive xylanase mutants were concentrated to $10 \mathrm{mg} / \mathrm{ml}$ in $25 \mathrm{mM}$ sodium acetate $(\mathrm{pH} 5.0)$ and crystallized at $4^{\circ} \mathrm{C}$ using the hanging drop vapour diffusion method. Protein and precipitant solutions were mixed 1:1 volume in the drop 
and equilibrated against $0.7 \mathrm{ml}$ of precipitant solution (Structure Screens 1 and 2 of Hampton Research, Aliso Viejo, CA, USA). For the B. subtilis E172A xylanase a crystal appeared after 8 months in $0.2 \mathrm{M}$ ammonium acetate, $0.1 \mathrm{M}$ Tris-hydrogen chloride buffer (pH 8.5) and 30\% (v/v) isopropanol (further referred to as XBS1) and after 1 year in $0.1 \mathrm{M}$ imidazole ( $\mathrm{pH} 6.5$ ) and 1.0 M sodium acetate trihydrate (XBS2), while for the $A$. niger E170A xylanase mutant crystals appeared after 3 to 4 days in $0.1 \mathrm{M}$ sodium chloride, 0.1 M Hepes buffer ( $\mathrm{pH} 7.5)$ and 1.6 M ammonium sulphate (XAN1). The crystals were used in soaking experiments with xylotetraose (Megazyme, Bray, Ireland) (for the XBS1 crystals), xylopentaose (Megazyme) (for the XAN1 crystals) or a mixture of arabinoxylo-oligosaccharides with an average degree of polymerization of 5 and an arabinose to xylose ratio of 0.52 (AXOS-5-0.52; for the XBS2 crystals). These AXOS were derived from Wheat Pentosan Concentrate (WPC, Pfeifer \& Langen, Dormagen, Germany) and were kindly obtained from Katrien Swennen (Laboratory of Food Chemistry and Biochemistry, K.U.Leuven, Belgium). In all cases a supersaturated solution $(30 \% \mathrm{w} / \mathrm{v}$ sugar) was used and soaking times ranged from 1 to 5 minutes. Crystals were then transferred briefly to a cryoprotectant composed of precipitant solution supplemented with $30 \%$ (v/v) glycerol and flash-cooled and stored under liquid nitrogen before data collection.

\section{Data collection, structure solution and refinement}

All X-ray diffraction data were collected at $100 \mathrm{~K}$ at the BW7a beam line of DESY, EMBL-Hamburg, Germany. The diffraction images were visualized using XDisplayF, processed using DENZO and scaled and merged using SCALEPACK from the HKL suite of programs [26]. All further computing used the CCP4 suite [27] unless otherwise stated. The structures were solved by molecular replacement using the program Phaser [28] for the XBS1 and XAN1 data while Molrep [29] was used for the XBS2 data. The Bacillus circulans xylanase with PDB-entry $1 \mathrm{BCX}[15]$ and the $A$. niger xylanase with PDB-entry IUKR [30] served as models for the B. subtilis and A. niger xylanase structures, respectively. Cycles of refinement and model building were performed using Refmac5 [31] and Coot [32] respectively. After several cycles of refinement, residual positive density in the $F_{o}-F_{c}$ and $2 F_{o}-F_{c}$ electron density maps revealed the presence of several 
bound sugar molecules, which were included in the models, followed by further refinement and manual addition of water molecules. The final structures were evaluated using SfCHECK [33] and root mean square (rms) deviations were calculated using the program SuperPose [34]. All data collection and refinement statistics are shown in Table 2. All figures were drawn using the program Pymol [35]. 


\section{Results}

\section{Overall structure of the soaked inactive xylanases.}

Insight in the binding of substrate in the active site of enzymes is of prime importance in understanding substrate specificity and related biochemical parameters. However, for GH 11 xylanases, only the binding of xylose residues in the glycon subsites of the active site has been crystallographically demonstrated. To explore the aglycon subsites, we produced inactive mutants of $B$. subtilis and $A$. niger xylanases. This was done by mutating the acid/base glutamate to an alanine and thus preventing the first step in the reaction mechanism. For the $B$. subtilis xylanase, this resulted in the E172A mutant, and for $A$. niger xylanase, in the E170A mutant.

For the B. subtilis xylanase mutant, crystals appeared in two crystallization conditions and are further referred to as XBS1 and XBS2. XBS1 crystals were soaked with xylotetraose while XBS2 crystals were soaked with a mixture of arabinoxylooligosaccharides with an average degree of polymerization of 5 and an average arabinose to xylose ratio of 0.52 (AXOS-5-0.52). For the A. niger xylanase mutant, one type of crystal could be grown (XAN1) which was soaked with xylopentaose. All structures could be solved by molecular replacement. Inspection of the electron density maps revealed clear density for xylose residues in the active site subsites of the XBS1 and XAN1 structures (Figures 1a-c). However, no extra interpretable density could be observed in the active site for the XBS2 structure indicating that the soak with AXOS-50.52 was not successful. This structure is further used as reference, i.e. ligand free structure. For both B. subtilis xylanase structures, the N-terminal amino acid could not be modeled because of the lack of good electron density suggesting that this region is disordered.

Electron densities corresponding to the bound xylo-oligosaccharides were not only found in the catalytic cleft. Instead, the electron density map also revealed a well-defined density corresponding to a xylo-oligosaccharide on the surface of the protein, for both $B$. subtilis and $A$. niger xylanases.

\section{The thumb region}


The overall structure of the ligand bound xylanases is very similar to those of ligand free structures as observed earlier for other species. When comparing both XBS1 and XBS2 with pdb-entry 2B46 [36], a B. subtilis xylanase not susceptible to TAXI inhibition in complex with xylobiose, the rms deviation for the $\mathrm{C} \alpha$ atoms is $0.7 \AA$ and $0.5 \AA$, respectively. A superposition of the ligand bound XBS1 and pdb-entry 2B46 structures on the one hand and the unbound XBS2 structure on the other hand reveals no displacement of the thumb region as can be deduced from the distance between the $\mathrm{C} \alpha$ atoms of $\mathrm{Asp}_{\mathrm{BS}} 119$ and $\mathrm{Asn}_{\mathrm{BS}}$ 35. This distance is $16.3 \AA$ for XBS1 and $17.1 \AA$ for XBS2 and 2B46. This is in contrast to earlier studies $[16,37]$ which state that xylanases adopt a closed conformation upon ligand binding. The here observed conformation of the enzyme is, however, necessary since in the closed conformation a xylose residue in the -3 subsite would clash with the tip of the thumb region.

For $A$. niger xylanase XAN1 compared with chain A of the ligand free, wild type structure (pdb-entry 1UKR) [30], the rms deviation is $0.3 \AA$ for the $\mathrm{C} \alpha$ atoms. Also for the XAN1 structure, no structural differences in the thumb region were observed. The distance between the $\mathrm{C} \alpha$ atoms of $\operatorname{Pro}_{\mathrm{AN}} 119$ and $\mathrm{Asp}_{\mathrm{AN}} 37$ is $11.3 \AA$ for the ligand free structure and $10.8 \AA$ for the ligand bound structure. This is in contrast with the opinion of Tahir and coworkers that the presence of a smaller thumb region (as in XAN) should not play a role in the motility of the thumb region upon substrate binding, i.e. that a smaller thumb region has an open-closed movement upon substrate binding [38].

\section{Xylo-oligosaccharide bound in the active site}

The XBS1 crystals contained two protein molecules in the asymmetric unit, named A (XBS1A) and B (XBS1B). Both monomers bind xylotetraose, but for XBS1A, xylose residues were observed in the $-3,-2$ and -1 subsites, while for XBS1B, they were observed in the $-2,-1$ and +1 subsites. As can be seen in Figures $1 \mathrm{a}$ and $1 \mathrm{~b}$, the xylose coordination was almost identical in the two monomers for the -2 and -1 subsites. The XAN1 crystal contained one monomer in the asymmetric unit. For this structure, only in the -2 and -1 subsite a xylose residue could be fitted in the electron density. The missing xylose residues probably extend beyond the active site cleft and are too mobile to be seen in the electron density. Table 3 and Figure 2 give an overview of all the interactions 
formed between the xylanases and its substrate. In what follows, the different subsites will be discussed in detail, starting with the -2 and -1 subsites, which are characterized best, followed by the -3 and +1 subsites, for which crystallographic data is presented for the first time.

\section{The -2 subsite}

At the -2 subsite, both for the B. subtilis (Figure 2a) and A. niger (Figure 2b) xylanases, an aromatic ring $\left(\operatorname{Trp}_{\mathrm{BS}} 9\right.$ and $\left.\operatorname{Tyr}_{\mathrm{AN}} 10\right)$ stacks against the xylopyranose ring which is in the chair conformation. Also, the hydrogen bond patterns are very similar for both xylanases. Two Tyr residues $\left(\operatorname{Tyr}_{\mathrm{BS}} 69-\mathrm{Tyr}_{\mathrm{AN}} 70\right.$ and $\left.\operatorname{Tyr}_{\mathrm{BS}} 166-\mathrm{Tyr}_{\mathrm{AN}} 164\right)$ are in a similar position and make hydrogen bonds with the $\mathrm{OH} 2$ and $\mathrm{OH} 3$ groups of the xylose. The length of one of these bonds (the hydrogen bond between $\mathrm{Tyr}_{\mathrm{BS}} 166$ and the $\mathrm{OH} 2$ group of xylose), differs by $0.4 \AA$ between XBS1A and XBS1B. This makes the bond in the XBS1B a stronger one. A Gln $\left(G \ln _{\mathrm{BS}} 7\right.$ and $\left.\mathrm{Gln} \ln _{\mathrm{AN}} 8\right)$ forms a weaker hydrogen bond with the $\mathrm{OH} 3$ group of xylose while the main chain atoms of the Ser and Pro at the tip of the thumb region form weaker hydrogen bonds with the endocyclic $\mathrm{O}$ and $\mathrm{OH} 1$ of the xylose.

\section{The -1 subsite}

In the -1 subsite, the interactions between the sugar and both the Pro ${ }_{\mathrm{BS}} 116 /$ Pro $_{\mathrm{AN}} 119$ and the nucleophilic Glu 78 / Glu 79 are analogous. The carbonyl group of the Pro is hydrogen bonded to the $\mathrm{OH} 3$ group of xylose and the Glu forms two hydrogen bonds with the $\mathrm{OH} 2$ of xylose. In $A$. niger xylanase, Asp 37 (which is responsible for its acidic character) is hydrogen bonded to the endocyclic oxygen and the $\mathrm{OH} 1$ group, while the analogous $\mathrm{Asn}_{\mathrm{BS}} 35$ (making this xylanase alkaline) makes only one hydrogen bond with $\mathrm{OH} 1$. This residue occupies a slightly different position than in the structures without the bound ligand. Both for B. subtilis and A. niger xylanases, the side chains of $\mathrm{Asn}_{\mathrm{BS}} 35$ and $\mathrm{Asp}_{\mathrm{AN}} 37$ are turned by $90^{\circ}$ in the absence of ligand. For the B. subtilis xylanase, this makes the distance between the residue and $\mathrm{OH} 1$ longer (from $3.3 \AA$ to 4.3 $\AA)$ and, consequently, impairs the formation of a hydrogen bond. For the A. niger xylanase, this rotation does not seem to cause any differences in the length of the 
hydrogen bonds between Asp $_{\mathrm{AN}} 37$ and the xylose residue. In $A$. niger xylanase, Tyr $_{\mathrm{AN}} 81$ and $\mathrm{Gln}_{\mathrm{AN}} 129$ are also hydrogen bonded to the xylose. In addition, the latter residue also makes a $2.8 \AA$ hydrogen bond with $\mathrm{O} \varepsilon$ of the nucleophile. In the B. subtilis xylanase, $\mathrm{Arg}_{\mathrm{BS}} 112$ makes several hydrogen bonds with the $\mathrm{OH} 2$ and $\mathrm{OH} 3$ groups of the xylose while, in $A$. niger xylanase, the analogous residue ( $\left.\operatorname{Arg}_{\text {AN }} 115\right)$ is turned away from the xylose. All these interactions make the xylose adopt a skew boat conformation in the $B$. subtilis xylanase (Figure 2c). Superposition with the native xylanase gives insight into the position and interactions of the acid/base glutamate. To this end, the A monomer of XBS1 was superposed with 2B46 [36] (Figure 2d) and XAN1 superposed with the A monomer of 1UKR [30] (Figure 2d). For both xylanases, O $\varepsilon$ of Glu 170 / Glu Bs 172 forms a strong hydrogen bond with the xylose which creates an ideal situation to initiate the reaction.

\section{The -3 subsite}

From the bound structure, subsite -3 , which is only observed in XBS1A (Figure 2e), seems to have a weak binding energy which probably reflects a less significant subsite. While subsites -2 and -1 show many interactions indicating tight binding, the xylose moiety of the -3 subsite forms only one weak hydrogen bond (the $\mathrm{OH} 4$ group of xylose with the carbonyl group of Ile $\mathrm{BS}$ 118). This interaction causes the xylose to adopt a boat conformation. To prevent the tip of the thumb region from clashing with the bound xylose residue, the thumb region can not adopt the closed conformation as proposed in earlier studies $[16,37]$.

The +1 subsite

XBS1B had a clear electron density corresponding to a xylose in the +1 subsite (Figure 2f) which makes this the first observation of a xylose residue in this subsite for GH 11 xylanases, showing substrate spanning the $-1 /+1$ subsites. The xylose moiety has a twist boat conformation which is mainly due to the hydrogen bonds between $\operatorname{Tyr}_{\mathrm{BS}} 80$ and the $\mathrm{OH} 1$ and $\mathrm{OH} 3$ groups of the xylose. An additional hydrogen bond is formed between the $\mathrm{OH} 2$ of xylose and the amide group of Gly $\mathrm{BS}_{\mathrm{BS}}$ 173. For the xylose to bind, Tyr 174 must flip away from the substrate. Furthermore, $\operatorname{Tyr}_{\mathrm{BS}} 88$, further down the aglycon subsites is 
also flipped. Superposing the XBS1B with the native xylanase (2B46) [36] revealed a clash between the xylose in the +1 subsite and the acid/base glutamate. In this structure, the latter is in the down position. To visualize the interactions between the xylose and the acid/base glutamate when this residue is in the up position, a superposition was made with the Trichoderma reesei xylanase II structure $1 \mathrm{XYO}$ from crystals grown at $\mathrm{pH} 4.5$ $[39,40]$. This structure revealed no clashes between the xylose in the +1 subsite and the acid/base glutamate indicating that this residue has to be in the up position for the substrate to bind substrate.

\section{Xylo-oligosaccharide bound to the surface}

Both for the B. subtilis and A. niger xylanases, there was a well-defined electron density corresponding to a xylo-oligosaccharide at the surface of the protein. For XBS1A and XBS1B, three xylose residues could be build in the density, while, for the A. niger structure, there was density for four xylose residues. In both structures, the xylooligosaccharide is bound to the finger region of the xylanase but in a different position (Figure 3). For the A. niger xylanase, it is bound to the tip of the finger region between $\beta$ strands A2 and A3, while for the B. subtilis xylanase it is found at the knuckles of the finger region between $\beta$-strands A4 and A5. For convenience, the binding subsites at the surface were numbered I, II and III starting from the reducing end of the xylooligosaccharide. Comparison between the xylanase structures shows that the direction in which the xylan is bound to the surface is the same: the reducing end is near the tip of the fingers while the non-reducing end is near the knuckles. Also, the binding of xylan to the surface does not seem to cause structural differences.

For B. subtilis xylanase, there seem to be three subsites at the surface to which xylose residues bind in their chair conformation. This is most obvious in XBS1A (Figure 4a) where a xylose residue is found in all three subsites. The $\mathrm{I}_{\mathrm{BS}}$ subsite is formed by $\mathrm{Asn}_{\mathrm{BS}}$ 54, Gly 56 ; $A s n_{B S} 181$ and $\mathrm{Thr}_{\mathrm{BS}}$ 183, which make hydrogen bonds to the xylose residue while in the $\mathrm{II}_{\mathrm{BS}}$ subsite $\mathrm{Asn}_{\mathrm{BS}} 54$ and $\mathrm{Asn}_{\mathrm{BS}} 141$ form the hydrogen bonds to the xylose. Table 4 gives an overview of all the interactions. The existence of the $\mathrm{III}_{\mathrm{BS}}$ subsite could be deduced from the electron density of a third xylose in XBS1A. This xylose makes a hydrophobic stacking interaction with $\operatorname{Trp}_{\mathrm{BS}} 185$. A. niger xylanase has a 
serine at this position making this interaction impossible. XBS1B (Figure 4b) contains an extra xylose residue beyond the $\mathrm{I}_{\mathrm{BS}}$ subsite which does not interact with the protein but has clear electron density and $B$-factors analogous to the other xylose residues bound to the surface. Comparison of this region of $B$. subtilis with the A. niger xylanase shows some structural differences. GlyBS 56 and $\mathrm{Asn}_{\mathrm{BS}} 141$ which make important hydrogen bonds both constitute insertions compared to A. niger xylanase.

For the $A$. niger structure, the presence of four xylose residues could be deduced from the electron density data (Figure $4 \mathrm{c}$ ). The xylose residue in the $\mathrm{I}_{\mathrm{AN}}$ subsite interacts with the carboxyl groups of $\mathrm{Asn}_{\mathrm{AN}} 13$ and Gly $\mathrm{AN}_{15}$, while in the $\mathrm{II}_{\mathrm{AN}}$ subsite Glu $\mathrm{AN} 31$ and $\mathrm{Asp}_{\mathrm{AN}}$ 32 form the interaction partners. Glu 31 is, together with Asp $_{\mathrm{AN}}$ 16, also important in the $\mathrm{III}_{\mathrm{AN}}$ subsite. In analogy with $B$. subtilis xylanase, all xylose residues adopt the chair conformation. Table 4 lists details on these interactions. In this region too, there are structural differences between the $B$. subtilis and $A$. niger xylanases. $\beta$-strand A2 in $A$. niger is much shorter compared to the analogous $\beta$-strand in B. subtilis. Hence, there is no corresponding residue for $\mathrm{Asn}_{\mathrm{AN}}$ 13, which is in the loop region at the end of $\beta$-strand A2, in B. subtilis. In analogy with the III subsite of B. subtilis xylanase, the xylose in the $\mathrm{III}_{\mathrm{AN}}$ subsite makes a hydrophobic stacking interaction, but with a tyrosine, $\mathrm{Tyr}_{\mathrm{AN}} 29$, instead of a tryptophan. B. subtilis xylanase does not have an aromatic residue at the corresponding position. The fourth residue is situated beyond subsite III $_{\mathrm{AN}}$ but does not form any interactions with the protein. 


\section{Discussion}

For the first time, crystallographic data of xylo-oligosaccharides bound to incompetent $B$. subtilis and $A$. niger xylanases are obtained. The data show substrate spanning the $-1 /+1$ subsites and revealed an extra binding site at the surface.

The xylose residue in the -1 subsite of $B$. subtilis xylanase seems to be slightly distorted towards a $\beta-{ }^{2} \mathrm{~S}_{\mathrm{O}}$ skew conformation (Figure $2 \mathrm{c}$ ). This is one of the two $\left({ }^{5} \mathrm{~S}_{1}\right.$ and $\left.{ }^{2} \mathrm{~S}_{\mathrm{O}}\right)$ conformations flanking the ${ }^{2,5} \mathrm{~B}$ conformation - which has been observed earlier $[14,17]$ - in the skew-boat pseudorotational series and provides support for the Deslongchampstype itinerary for the glycosylation step of GH11 $\left(\beta-{ }^{2} \mathrm{~S}_{\mathrm{O}} \rightarrow \mathrm{E}_{3}-\mathrm{TS} \rightarrow \alpha-{ }^{4} \mathrm{C}_{1}\right.$ glycosyl enzyme intermediate) postulated by Nerincks and co-workers. The proposed deglycosylation step would then go through a re-entry into the skew-boat pseudorotational series: $\alpha-{ }^{5} \mathrm{~S}_{1} \rightarrow \mathrm{E}_{4}-\mathrm{TS} \rightarrow \beta-{ }^{1} \mathrm{C}_{4}[41]$.

For both B. subtilis and A. niger xylanase, superposition of substrate bound and unbound structures does not show the expected difference between the earlier observed open and closed conformations observed for Trichoderma reesei xylanase [16, 37]. This may indicate that this difference in conformation is species dependent, and therefore, is not a general property of GH family 11 xylanases. For $A$. niger this difference is probably due to the shorter thumb region, while for $B$. subtilis it is due to the -3 subsite, as the xylose residue at this subsite would clash with the tip of the thumb region if the xylanase adopts the closed conformation upon substrate binding.

For A. niger xylanase, the main end products from the hydrolysis of xylooligosaccharides are xylobiose and xylotriose [42], while for B. subtilis, there is no information on the hydrolysis of xylo-oligosaccharides. As can be seen from the superposition of XBS and XAN, there is little difference in substrate binding in the glycon subsites. This may point out that differences between hydrolyzing products would be due to the aglycon subsites or to subtle changes at the glycon subsites. This needs further analyzing.

Inspection of the different subsites may further explain the failed attempt to soak XBS2 with AXOS-5-0.52. It was seen that for the $-2,-1$ and +1 subsite, no arabinose substitution on the xylan backbone is acceptable because of sterical hindrance: the tip of the thumb region makes the active site cleft nearly tunnel-shaped near the -2 and -1 
subsites. Hence, AXOS-5-0.52 with an average arabinose to xylose ratio of 0.52 probably has too many substitutions to allow for binding.

Both for the B. subtilis and A. niger xylanase, a xylo-oligosaccharide was found to be bound to the surface. This is also seen for a family 8 xylanase from Pseudoaltermomas haloplanktis having an $(\alpha / \alpha)_{6}$ fold [43]. Also within GH family 11, this was already observed for an $A$. niger xylanase [36] and a B. circulans xylanase [44]. These data suggest that this extra binding site has a physiological meaning and is not only due to the high concentrations during the soaking experiment. A possible function, previously suggested by Törrönen and co-workers may be one similar to the separate carbohydrate binding domains of other glycoside hydrolase families, i.e. increasing the effective concentration of the active site on polymeric substrate [5]. This was recently confirmed by Ludwiczek and coworkers who revealed the presence of a xylan-specific secondary binding site at the surface of $B$. circulans xylanase using NMR-monitored titrations. They proposed that the active site and the secondary binding site function cooperatively to enhance the activity towards longer substrates [44].

Superposition of the subsites at the surface shows large differences between the xylanases of $B$. subtilis and A. niger in the position where the xylose residues bind. This corresponds to the assumption of Ludwiczek and coworkers who suggest that different regions of the Ser/Thr-rich surface in different xylanases also function as secondary binding sites [44]. Not only the location of the secondary binding site differs, also the position where arabinose substitution is possible varies. For B. subtilis xylanase, in the $\mathrm{II}_{\mathrm{BS}}$ and $\mathrm{III}_{\mathrm{BS}}$ subsites, arabinose substitution is possible. For $A$. niger xylanase, in the $\mathrm{I}_{\mathrm{AN}}$ subsite, an arabinose is possible only on the $\mathrm{OH} 3$ of the xylose residue. In the $\mathrm{II}_{\mathrm{AN}}$ subsite, there is no possibility for arabinose substitution, and, in the $\mathrm{III}_{\mathrm{AN}}$ subsite, both $\mathrm{OH} 2$ and/or $\mathrm{OH} 3$ can be substituted. These differences may suggest that the binding of xylan to the surface may play a role in substrate specificity.

Earlier mutation studies of Moers and coworkers suggested a role in substrate selectivity for some surface exposed aromatic residues in B. subtilis xylanase. Mutation of $\operatorname{Trp}_{\mathrm{BS}} 185$ to an alanine revealed a significantly lower selectivity of the enzyme towards waterunextractable arabinoxylans [45]. The here observed binding site at the surface strongly 
supports the proposed role of this region as playing a role in substrate selectivity and specificity, although further mutation analysis should be performed. 


\section{Acknowledgements}

We thank the staff of the EMBL/DESY Hamburg Outstation for the provision of synchrotron facilities and skillful technical assistance and financial support through the I3 contract with the European Commission for support of access for external users. We also would like to thank Dr. Wim Nerinckx (Universiteit Gent, Belgium) for the discussion on sugar conformations. This work was funded by the Flemish IWT (Instituut voor de aanmoediging van Innovatie door Wetenschap en Technologie in Vlaanderen, SBO project funding, Impaxos, and the scholarship to S. Rombouts), the Flemish FWO (Fonds voor Wetenschappelijk Onderzoek Vlaanderen, post-doctoral fellowhip to Dr. A. Rabijns) and the 'Bijzonder Onderzoeksfonds K.U.Leuven' (post-doctoral fellowship to Dr. S. Van Campenhout). 


\section{References}

1 Whistler, R. L. and Richards, E. L. (1990) Hemicelluloses. In The carbohydrates chemistry and biochemistry (Pigman, W. and Horton, D., eds.). pp. 447-469, Academic Press, New York

2 Jeffries, T. W. (1994) Biodegradation of lignin and hemicelluloses. In Biochemistry of Microbial Degradation. (Ratledge, C., ed.). pp. 233-277, Kluwer Academic Publishers, The Netherlands

3 Henrissat, B., Teeri, T. T. and Warren, R. A. J. (1998) A scheme for designating enzymes that hydrolyse the polysaccharides in the cell walls of plants. FEBBS Lett. 425, $352-354$

4 Harris, G. W., Jenkins, J. A., Connerton, I., Cummings, N., Leggio, L. L., Scott, M., Hazlewood, G. P., Laurie, J. I., Gilbert, H. J. and Pickersgill, R. W. (1994) Structure of the catalytic core of the family $\mathrm{F}$ xylanase from Pseudomonas fluorescens and identification of the xylopentaose-binding sites. Structure. 2, 1107-1116

5 Törrönen, A., Harkki, A. and Rouvinen, J. (1994) Three-dimensional structure of endo-1,4-beta-xylanase II from Trichoderma reesei: two conformational states in the active site. EMBO Journal. 13, 2493-2501

6 Biely, P., Vrsanska, M., Tenkanen, M. and Kluepfel, D. (1997) Endo-beta-1,4xylanase families: differences in catalytic properties. J. Biotechnol. 57, 151-166

7 Moers, K., Celis, I., Brijs, K., Courtin, C. M. and Delcour, J. A. (2005) Endoxylanase substrate selectivity determines degradation of wheat water-extractable and water-unextractable arabinoxylan. Carbohyd. Res. 340, 1319-1327

8 Pell, G., Szabo, L., Charnock, S. J., Xie, H., Gloster, T. M., Davies, G. J. and Gilbert, H. J. (2004) Structural and biochemical analysis of Cellvibrio japonicus xylanase 10C. J. Biol. Chem. 279, 11777-11788

9 Ko, E. P., Akatsuka, H., Moriyama, H., Shinmyo, A., Hata, Y., Katsube, Y., Urabe, I. and Okada, H. (1992) Site-directed mutagenesis at aspartate and glutamate residues of xylanase from Bacillus pumilis. Biochem. J. 288, 117-121

10 Sinnott, M. L. (1990) Catalytic mechanism of enzymic glycosyl transfer. Chem. Rev. 90, 1171-1202 
11 Vyas, N. K., Vyas, M. N. and Quiocho, F. A. (1991) Comparison of the periplasmic receptors for L-arabinose, D-glucose/D-galactose and D-ribose. Structural and functional similarity. J. Biol. Chem. 266, 5226-5237

12 Davies, G. J., Wilson, K. S. and Henrissat, B. (1997) Nomenclature for sugarbinding subsites in glycosyl hydrolases. Biochem. J. 321, 557-559

13 Joshi, M. D., Sidhu, G., Pot, I., Brayer, G. D., Withers, S. G. and McIntosh, L. P. (2000) Hydrogen bonding and catalysis: a novel explanation for how a single amino acid substitution can change the $\mathrm{pH}$ optimum of a glycosidase. J. Mol. Biol. 299, 255-279

14 Sidhu, G., Withers, S. G., Nguyen, N. T., McIntosh, L. P., Ziser, L. and Brayer, G. D. (1999) Sugar ring distortion in the glycosyl-enzyme intermediate of a family GH 11 xylanase. Biochemistry. 38, 5346-5354

15 Wakarchuk, W. W., Campbell, R. L., Sung, W. L., Davoodi, J. and Yaguchi, M. (1994) Mutational and crystallographic analysis of the active site residues of the Bacillus circulans xylanase. Prot. Science. 3, 467-475

16 Havukainen, R., Törrönen, A., Laitinen, T. and Rouvinen, J. (1996) Covalent binding of three epoxyalkyl xylosides to the actiye site of endo-1,4-xylanase II from Trichoderma reesei. Biochemistry. 35, 9617-9624

17 Sabini, E., Sulzenbacher, G., Dauter, M., Dauter, Z., Jorgensen, P. L., Schülein, M., Dupont, C., Davies, G. J. and Wilson, K. S. (1999) Catalysis and specificity in enzymatic glycoside hydrolysis: a ${ }^{2,5} \mathrm{~B}$ conformation for the glycosyl-enzyme intermediate revealed by the structure of the Bacillus agaradhaerens family 11 xylanase. Chem. Biol. 6, 483-492

18 Sabini, E., Wilson, K. S., Danielsen, S., Schülein, M. and Davies, G. J. (2001) Oligosaccharide binding to family 11 xylanases: both covalent intermediate and mutant product complexes display ${ }^{2,5} \mathrm{~B}$ conformations at the active centre. Acta Crystallogr. D57, 1344-1347

19 Jänis, J., Hakanpää, J., Hakulinen, N., Ibatulin, F. M., Hoxha, A., Derrick, P. J., Rouvinen, J. and Vainiotalo, P. (2005) Determination of thioxylo-oligosaccharide binding to family 11 xylanases using electrospray ionization Fourier transform ion cyclotron resonance mass spectrometry and X-ray crystallography. FEBBS Journal. 272, 23172333 
20 De Lemos Esteves, F., Ruelle, V., Lamotte-Brasseur, J., Quinting, B. and Frère, J. M. (2004) Acidophilic adaptation of family 11 endo-beta-1,4-xylanases: modeling and mutational analysis. Prot. Science. 13, 1209-1218

21 Gruber, K., Klintschar, G., Hyan, M., Schlacher, A., Steiner, W. and Kratky, C. (1998) Thermophilic xylanase from Thermomyces lanuginosus: high-resolution X-ray structure and modeling studies. Biochemistry. 37, 13475-13485

22 Sapag, A., Wouters, J., Lambert, C., de Ioannes, P., Eyzaguirre, J. and Depiereux, E. (2002) The endoxylanases from family 11: computer analysis of protein sequences reveals important structural and phylogenetic relationships. J. Biotechnol. 95, 109-131

23 Hertveldt, K., Dechassa, M. L., Robben, J. and Volckaert, G. (2003) Identification of Gal80p-interacting proteins by Saccharomyces cerevisiae whole genome phage display. Gene. 307, 141-149

24 Smith, A. M. and Klugman, K. P. (1997) "Megaprimer" method of PCR-based mutagenesis: the concentration of megaprimer is a critical factor. Bioctechniques. 22, $438-442$

25 Beliën, T., Hertveldt, K., Van Den Brande, K., Robben, J., Van Campenhout, S. and Volckaert, G. (2005) Functional display of family 11 endoxylanases on the surface of phage M13. J. Biotechnol. 115, 249-260

26 Otwinowski, Z. and Minor, W. (1997) Processing of X-ray diffraction data collected in oscillation mode. In Methods in enzymology, volume 276: Macromolecular crystallography, part A (Carter, C. W. and Sweet, J. R. M., eds.). pp. 307-326, Academic Press, New York

27 Collaborative Computational Project Number 4. (1994) The CCP4 suite: programs for protein crystallography. Acta Crystallogr. D50, 760-763

28 McCoy, A. J., Grosse-Kunstleve, R. W., Storoni, L. C. and Read, R. J. (2005) Likelihood-enhanced fast translation functions. Acta Crystallogr. D61, 458-464

29 Vagin, A. A. and Teplyakov, A. (1997) Molrep: an automated program for molecular replacement. J. Appl. Cryst. 30, 1022-1025

30 Krengel, U. and Dijkstra, B. W. (1996) Three-dimensional structure of endo-1,4beta-xylanase I from Aspergillus niger: molecular basis for its low $\mathrm{pH}$ optimum. J. Mol. Biol. 263, 70-78 
31 Murshudov, G. N., Vagin, A. A. and Dodson, E. J. (1997) Refinement of molecular structures by the maximum-likelihood method. Acta Crystallogr. D53, 240-255 32 Emsley, P. and Cowtan, K. (2004) Coot: model-building tools for molecular graphics. Acta Crystallogr. D60, 2126-2132

33 Vaguine, A. A., Richelle, J. and Wodak, S. J. (1999) SFCHECK: a unified set of procedure for evaluating the quality of macromolecular structure-factor data and their agreement with atomic model. Acta Crystallogr. D55, 191-205

34 Maiti, R., Van Domselaar, G. H., Zhang, H. and Wishart, D. S. (2004) SuperPose: a simple server for sophisticated structural superposition. Nucleic Acid Research. 32, W590-W594

35 Delano, W. L. (2004) The PyMol molecular graphics system. DeLano Scientific, LLC, Sanc Carlos, CA

36 Sansen, S. (2005) Towards a better understanding of xylanase inhibition by TAXI-type proteins: a crystallographic study. In Department of Pharmaceutical Sciences ed. $)^{\wedge}$ eds.), Katholieke Universiteit Leuven, Leuven

37 Muili, J., Törrönen, A., Perakylä, M. and Rouvinen, J. (1998) Functional conformational changes of endo-1,4-xylanase II from Trichoderma reesei: a molecular dynamics study. Proteins. 31, 434-444

38 Tahir, T. A., Berrin, J. G., Flatman, R., Roussel, A., Roepstorff, P., Williamson, G. and Juge, N. (2002) Specific characterization of substrate and inhibitor binding sites of a glycosyl hydrolase family 11 xylanase from Aspergillus niger. J. Biol. Chem. 277, 44035-44043

39 Törrönen, A. and Rouvinen, J. (1995) Structural comparison of two major endo1,4-xylanases from Trichoderma reesei. Biochemistry. 34, 847-856

40 Törrönen, A., Rouvinen, J., Ahlegren, M., Harkki, A. and Visuri, K. (1993) Crystallization and preliminary X-ray analysis of two major xylanases from Trichodermi reesei. J. Mol. Biol. 233, 313-316

41 Nerinckx, W., Desmet, T. and Claeyssens, M. (2006) Itinaries of enzymatically and non-enzymatically catalyzed substitutions at $O$-glycopyranosidic bonds. ARKIVOC. $13,90-116$ 
42 Berrin, J. G., Ajandouz, E. H., Georis, J., Arnout, F. and Juge, N. (2006) Substrate and product hydrolysis specificity in family 11 glycoside hydrolases: an analysis of Penicillium funiculosum and Penicillium griseofulvum xylanases. Appl. Microbiol. Biotechnol. 74, 1001-1010

43 De Vos, D., Collins, T., Nerinckx, W., Savvides, S. N., Claeyssens, M., Gerday, C., Feller, G. and Van Beeumen, J. (2006) Oligosaccharide binding in family 8 glycosidases: crystal structures of active site mutants of the beta-1,4-xylanase $\mathrm{pXyl}$ from Pseudoalteromonas haloplanktis TAH3a in complex with substrate and product. Biochemistry. 45, 4797-4807

44 Ludwiczek, M. L., Heller, M., Kantner, T. and McIntosh, L. P. (2007) A secondary xylan-binding site enhances the catalytic activity of a single-domain family 11 glycoside hydrolase. J. Mol. Biol. 373, 337-354

45 Moers, K., Bourgois, T., Rombouts, S., Beliën, T., Van Campenhout, S., Volckaert, G., Robben, J., Brijs, K., Delcour, J. A. and Courtin, C. M. (2007) Alteration of Bacillus subtilis XynA endoxylanase substrate selectivity by site-directed mutagenesis. Enzyme Microbiol. Tech. 41, 85-91 
Table 1: Oligonucleotide primers used for the construction of the inactive $B$. subtilis and $A$. niger xylanase mutants.

\begin{tabular}{ll}
\hline Primer & Sequence 5' $\rightarrow \mathbf{3}^{\prime}$ \\
\hline B. subtilis & \\
BsXynAf02 & CACAGATCTGCTGGCACAGATTACTGG \\
BsXynAr03 & CACAGATCTTTACCACACTGTTACATTAGAAC \\
BsE172Ar & CTACTTTGATATCC TGCTGTCGCCATGAC \\
& \\
A. niger & \\
AnExf02 & CACAGATCTAGTGCCGGTATCAAC \\
AnExr02 & CACAGATCTAGAAGAGATCGTGACACT \\
AnE170Ar & CTCCATGCTGCCACCGCCAC \\
AnExrstop & CACAGATCTTTAAGAGGAGATCGTGAC \\
\hline
\end{tabular}

The $B g l$ II restriction site is in bold and the mutagenic bases are in italic and underlined. 
Table 2: Data collection and refinement statistics

\begin{tabular}{|c|c|c|c|}
\hline & $\begin{array}{c}\text { Bacillus subtilis } \\
\text { E172A xylanase } \\
\text { soaked with } \\
\text { xylotetraose (XBS1) }\end{array}$ & $\begin{array}{c}\text { Bacillus subtilis } \\
\text { E172A xylanase } \\
\text { soaked with AX5 } \\
\text { (XBS2) }\end{array}$ & $\begin{array}{c}\text { Aspergillus niger } \\
\text { E170A xylanase } \\
\text { soaked with } \\
\text { xylopentaose } \\
\text { (XAN1) }\end{array}$ \\
\hline \multicolumn{4}{|l|}{ Data collection } \\
\hline Wavelength $(\AA)$ & 0.9762 & 0.9918 & 0.9918 \\
\hline Resolution range $(\AA)$ & $20-1.8(1.83-1.80)$ & $30-1.3(1.32-1.30)$ & $30-2.8(2.85-2.80)$ \\
\hline \multicolumn{4}{|l|}{ Reflections } \\
\hline Observed & 100440 & 312797 & 31374 \\
\hline Unique & $30942(1547)$ & $70534(3109)$ & $5843(271)$ \\
\hline Completeness $(\%)$ & $99.4(99.9)$ & $89.7(80.2)$ & $98.2(98.2)$ \\
\hline Average $\mathrm{I} / \sigma$ & $23.3(11.5)$ & $18(5.7)$ & $13.7(5.3)$ \\
\hline $\mathrm{R}_{\mathrm{sym}}(\%)$ & $4.4(8.9)$ & $8.6(16.5)$ & $9.4(30.2)$ \\
\hline Multiplicity & $3.2(3.5)$ & $4.4(4.5)$ & $5.4(5.7)$ \\
\hline Crystal & $P 2_{1}$ & $P 2_{1} 2_{1} 2_{1}$ & $P 6_{1} 22$ \\
\hline Space group & $a=40.6 \AA$ & $a=40.9 \AA$ & $a=67.2 \AA$ \\
\hline \multirow[t]{2}{*}{ Cell dimensions } & $b=79.0 \AA$ & $b=63.1 \AA$ & $b=67.2 \AA$ \\
\hline & $\begin{array}{l}c=54.4 \AA \\
\beta=101.5^{\circ}\end{array}$ & $c=122.4 \AA$ & $c=165.2 \AA$ \\
\hline Molecules/asu & & 2 & 1 \\
\hline \multicolumn{4}{|l|}{ Refinement } \\
\hline $\mathrm{R}_{\text {work }}(\%)$ & 14.6 & 15.7 & 22.1 \\
\hline $\mathrm{R}_{\text {free }}(\%)$ & 18.8 & 17.6 & 27.7 \\
\hline Reflections in the $\mathrm{R}_{\text {free }}$ set & 3117 & 3552 & 542 \\
\hline \multicolumn{4}{|l|}{ Rms deviations } \\
\hline Bond lengths $(\AA)$ & 0.011 & 0.006 & 0.006 \\
\hline Bond angles $\left({ }^{\circ}\right)$ & 1.343 & 1.170 & 1.005 \\
\hline \multicolumn{4}{|l|}{ Number of atoms } \\
\hline Protein & $1450^{\mathrm{A}} / 1460^{\mathrm{B}}$ & $1467^{\mathrm{A}} / 1456^{\mathrm{B}}$ & 1402 \\
\hline Solvent & 295 & 350 & 37 \\
\hline \multirow{2}{*}{ Ligand } & $38^{\mathrm{A}} / 28^{\mathrm{B} *}$ & & $19 *$ \\
\hline & $28^{\mathrm{A}} / 28^{\mathrm{B} * *}$ & & $37 * *$ \\
\hline \multicolumn{4}{|l|}{ Average B-factor $\left(\AA^{2}\right)$} \\
\hline Main chain & $12.3^{\mathrm{A}} / 11.0^{\mathrm{B}}$ & $11.0^{\mathrm{A}} / 10.9^{\mathrm{B}}$ & 23.5 \\
\hline Side chain & $13.8^{\mathrm{A}} / 12.3^{\mathrm{B}}$ & $12.1^{\mathrm{A}} / 12.0^{\mathrm{B}}$ & 23.2 \\
\hline Solvent & 26.4 & 22.3 & 18.8 \\
\hline Ligand & $35.9^{\mathrm{A}} / 32.6^{\mathrm{B} *}$ & & $63.5^{*}$ \\
\hline & $38.3^{\mathrm{A}} / 28.2^{\mathrm{B} * *}$ & & $23.6^{*}$ \\
\hline PDB-code & 2QZ3 & $2 Z 79$ & 2QZ2 \\
\hline
\end{tabular}

Values in parentheses are for the highest resolution shell.

A/B Refer to the A and B momomer, respectively.

* This value is for the ligand at the active site.

* This value is for the ligand bound at the surface. 
Table 3: Summary of the contacts between Bacillus subtilis E172A and Aspergillus niger E170A xylanase and their substrate in the active site.

Bacillus subtilis E172A xylanase

\begin{tabular}{|c|c|c|c|c|c|c|c|}
\hline \multirow{3}{*}{ Subsite } & \multicolumn{5}{|c|}{ Bacillus subtilis E172A xylanase } & \multicolumn{2}{|c|}{$\begin{array}{c}\text { Aspergillus niger E170 } \\
\text { xylanase }\end{array}$} \\
\hline & \multirow{2}{*}{$\begin{array}{l}\text { Substrate } \\
\text { atom }\end{array}$} & \multirow{2}{*}{ Protein atom } & \multicolumn{2}{|c|}{ Distance $(\AA)$} & \multirow{2}{*}{$\begin{array}{l}\text { Substrate } \\
\text { atom }\end{array}$} & \multirow{2}{*}{ Protein atom } & \multirow{2}{*}{$\begin{array}{l}\text { Distance } \\
(\AA)\end{array}$} \\
\hline & & & A monomer & B monomer & & & \\
\hline-3 subsite & $\mathrm{O} 4$ & Ile $118 \mathrm{CO}$ & 3.4 & & & & \\
\hline \multirow[t]{8}{*}{-2 subsite } & $\mathrm{O} 1$ & Pro $116 \mathrm{CO}$ & 3.5 & 3.3 & $\mathrm{O} 1$ & Pro $119 \mathrm{CO}$ & 3.4 \\
\hline & $\mathrm{O} 2$ & Tyr $69 \mathrm{OH}$ & 3.0 & 3.1 & $\mathrm{O} 2$ & Tyr $70 \mathrm{OH}$ & 3.0 \\
\hline & $\mathrm{O} 2$ & Tyr $166 \mathrm{OH}$ & 3.3 & 2.9 & 02 & $\mathrm{G} \ln 8 \mathrm{O} \varepsilon$ & 3.4 \\
\hline & $\mathrm{O} 3$ & Tyr $166 \mathrm{OH}$ & 2.6 & 2.6 & $\mathrm{O} 3$ & Tyr $164 \mathrm{OH}$ & 2.7 \\
\hline & $\mathrm{O} 3$ & $\mathrm{G} \ln 7 \mathrm{~N} \varepsilon$ & 3.3 & 3.4 & $\mathrm{O} 3$ & $\mathrm{Gln} 8 \mathrm{~N} \varepsilon$ & 3.5 \\
\hline & $\mathrm{O} 5$ & Pro $116 \mathrm{CO}$ & 3.5 & 3.5 & $\mathrm{O} 3$ & $\mathrm{G} \ln 8 \mathrm{O} \varepsilon$ & 3.5 \\
\hline & O5 & Pro $117 \mathrm{~N}$ & 3.2 & 3.5 & O5 & Ser $120 \mathrm{CO}$ & 3.2 \\
\hline & & & & & O5 & Ser $120 \mathrm{~N}$ & 3.5 \\
\hline \multirow[t]{8}{*}{-1 subsite } & $\mathrm{O} 1$ & Asn $35 \mathrm{O} \delta$ & 3.3 & 3.0 & $\mathrm{O} 1$ & Asp $37 \mathrm{O} \delta 1$ & 3.1 \\
\hline & $\mathrm{O} 2$ & Glu 78 O $\varepsilon 1$ & 2.9 & 30 & $\mathrm{O} 1$ & Asp 37 O $\delta 2$ & 3.4 \\
\hline & $\mathrm{O} 2$ & Glu 78 O $\varepsilon 2$ & 3.0 & 2.8 & $\mathrm{O} 1$ & Tyr $81 \mathrm{OH}$ & 3.3 \\
\hline & $\mathrm{O} 2$ & $\operatorname{Arg} 112 \mathrm{~N} \varepsilon$ & 3.5 & 3.2 & $\mathrm{O} 2$ & Glu 79 O $\varepsilon 1$ & 3.2 \\
\hline & $\mathrm{O} 3$ & Pro $116 \mathrm{CO}$ & 2.6 & 2.6 & $\mathrm{O} 2$ & Glu 79 O 22 & 3.3 \\
\hline & $\mathrm{O} 3$ & Arg 112 NH2 & 3.0 & 2.9 & $\mathrm{O} 2$ & Gln $129 \mathrm{~N} \varepsilon$ & 3.3 \\
\hline & $\mathrm{O} 3$ & $\operatorname{Arg} 112 \mathrm{~N} \varepsilon$ & & 3.2 & $\mathrm{O} 3$ & Pro $119 \mathrm{CO}$ & 2.6 \\
\hline & & & & & $\mathrm{O} 5$ & Asp $37 \mathrm{O} \delta 2$ & 3.0 \\
\hline \multirow[t]{3}{*}{+1 subsite } & $\mathrm{O} 1$ & Tyr $80 \mathrm{OH}$ & & 2.7 & & & \\
\hline & $\mathrm{O} 2$ & Gly $173 \mathrm{~N}$ & & 3.2 & & & \\
\hline & $\mathrm{O} 3$ & Tyr $80 \mathrm{OH}$ & & 2.7 & & & \\
\hline
\end{tabular}


Table 4: Summary of the interactions between the incompetent xylanase and the xylo-oligosaccharides bound to the surface.

\begin{tabular}{|c|c|c|c|}
\hline Subsite & Substrate atom & Protein atom & Distance $(\AA)$ \\
\hline \multicolumn{4}{|c|}{ Bacillus subtilis E712A xylanase } \\
\hline \multirow[t]{6}{*}{ I subsite } & $\mathrm{O} 2$ & Asn $181 \mathrm{~N} \delta 2$ & \\
\hline & $\mathrm{O} 2$ & Asn $181 \mathrm{CO}$ & 3.1 \\
\hline & $\mathrm{O} 2$ & Gly $56 \mathrm{~N}$ & 3.0 \\
\hline & $\mathrm{O} 3$ & Thr $183 \mathrm{O} \gamma 1$ & 2.7 \\
\hline & $\mathrm{O} 3$ & Thr $183 \mathrm{~N}$ & 3.4 \\
\hline & $\mathrm{O} 3$ & Asn $54 \mathrm{CO}$ & 2.6 \\
\hline \multirow[t]{3}{*}{ II subsite } & $\mathrm{O} 1$ & Asn $54 \mathrm{O} \delta 1$ & 3.5 \\
\hline & $\mathrm{O} 3$ & Asn $141 \mathrm{~N} \delta 2$ & 3.1 \\
\hline & $\mathrm{O} 3$ & Asn $141 \mathrm{O} \delta$ & 3.4 \\
\hline \multicolumn{2}{|l|}{ III subsite } & $\operatorname{Trp} 185$ & Hydrophobic stacking \\
\hline \multicolumn{4}{|c|}{ Aspergillus niger E170A xylanase } \\
\hline \multirow[t]{2}{*}{ I subsite } & $\mathrm{O} 2$ & Asn $13 \mathrm{CO}$ & 2.9 \\
\hline & $\mathrm{O} 3$ & Gly $15 \mathrm{CO}$ & 2.8 \\
\hline \multirow[t]{4}{*}{ II subsite } & $\mathrm{O} 2$ & Asp $32 \mathrm{~N}$ & 2.9 \\
\hline & $\mathrm{O} 2$ & Glu $31 \mathrm{~N}$ & 3.1 \\
\hline & $\mathrm{O} 3$ & Glu $31 \mathrm{~N}$ & 2.8 \\
\hline & & Glu 31 O $\varepsilon 1$ & 2.8 \\
\hline \multirow[t]{4}{*}{ III subsite } & & Glu 31 O $\varepsilon 1$ & 3.5 \\
\hline & 2 & Asp $160 \delta 2$ & 2.7 \\
\hline & O5 & Glu $31 \mathrm{O} \varepsilon 1$ & 2.9 \\
\hline & & Tyr 29 & Hydrophobic stacking \\
\hline
\end{tabular}




\section{Figure legends}

\section{Figure 1}

View of the substrate bound to the active site cleft of (a) the A monomer of the E172A $B$. subtilis mutant, (b) the B monomer of the B. subtilis mutant, and (c) the E170A A. niger xylanase mutant. The $2 F_{o}-F_{c}$ electron density maps are contoured at $1.0 \sigma$.

\section{Figure 2}

Detailed view of the active site subsites. (a) and (b) View of the -2 subsite of the $B$. subtilis and A. niger xylanase, respectively. (c) Detail of the -1 subsite of the A monomer of the B. subtilis xylanase superimposed with the wild type structure (pdb-entry 2B46) to show the position of Glu 172 (blue). (d) Detail of the -1 subsite of the $A$. niger xylanase mutant superimposed with the wild type (pdb-entry $1 \mathrm{UKR}$ ) to see the position of the $\mathrm{Glu}_{\mathrm{AN}} 170$ (blue). The small panel shows the $\beta-{ }^{2} \mathrm{~S}_{\mathrm{O}}$ skew conformation of the sugar. (e) Detail of the -3 subsite which is only visible in the A monomer of the B. subtilis xylanase mutant. (f) Interactions in the +1 subsite of the B. subtilis xylanase B monomer.

\section{Figure 3}

Superposition of the $A$. niger xylanase mutant (green) and the A monomer of the $B$. subtilis xylanase mutant (blue). The binding subsites at the surface are numbered I, II and III starting from the reducing end of the xylo-oligosaccharide. (a) Side view of the xylanase superposition. (b) Top view showing the position of the xylo-oligosaccharide bound to the surface.

\section{Figure 4}

(a,b) Hydrogen-bonding pattern of xylotetraose bound to the surface of the A momomer and $\mathrm{B}$ monomer of the B. subtilis xylanase mutant respectively. (c) Hydrogen-bonding pattern for the xylopentaose bound to the surface of the $A$. niger xylanase mutant. The $2 F_{o}-F_{c}$ electron density maps are contoured at $1.0 \sigma$. 


\section{Figure 1}
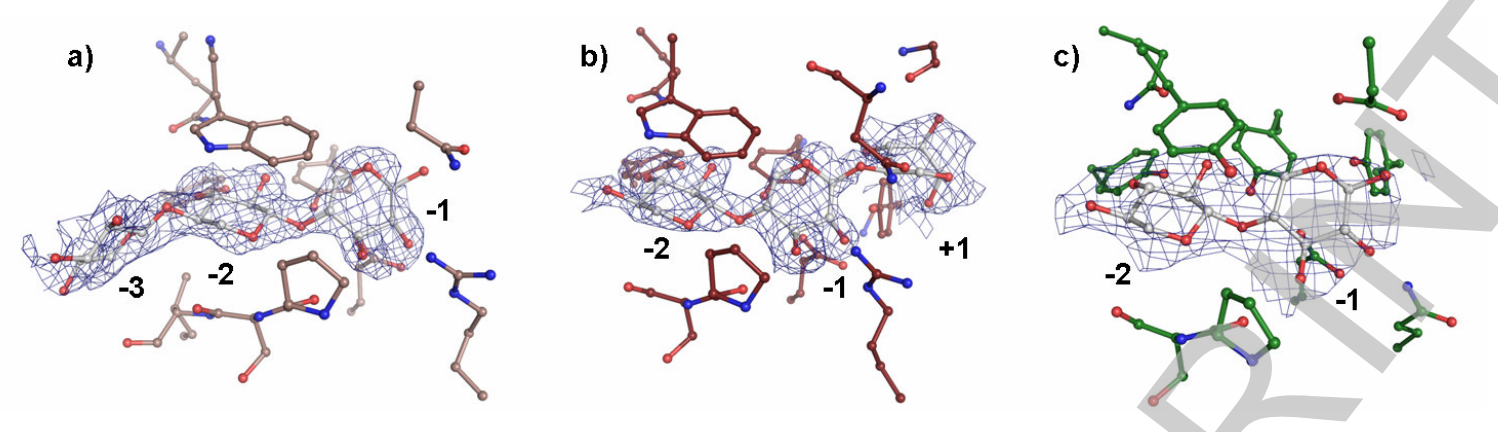


\section{Figure 2}

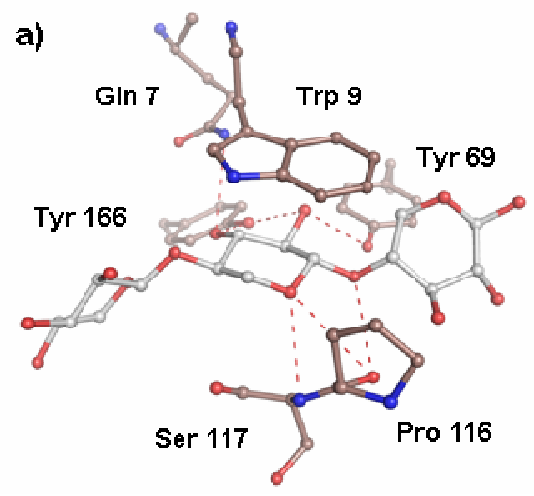

b)

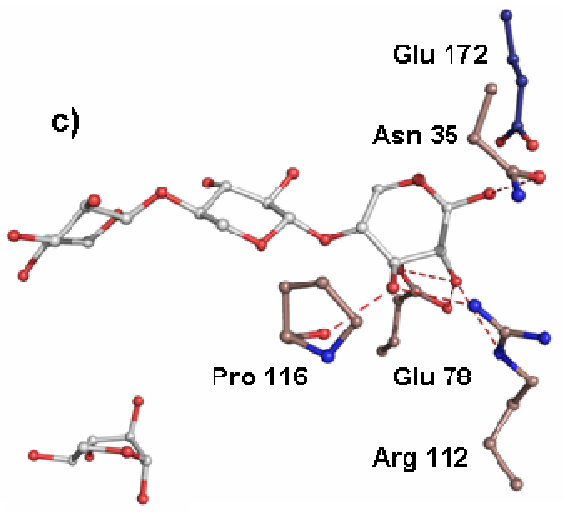

e)
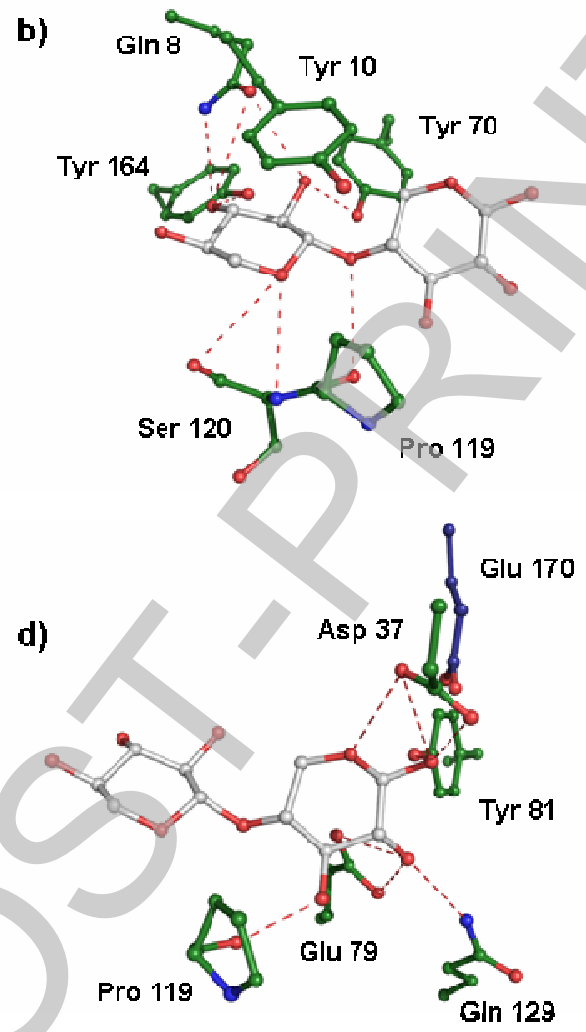

f)
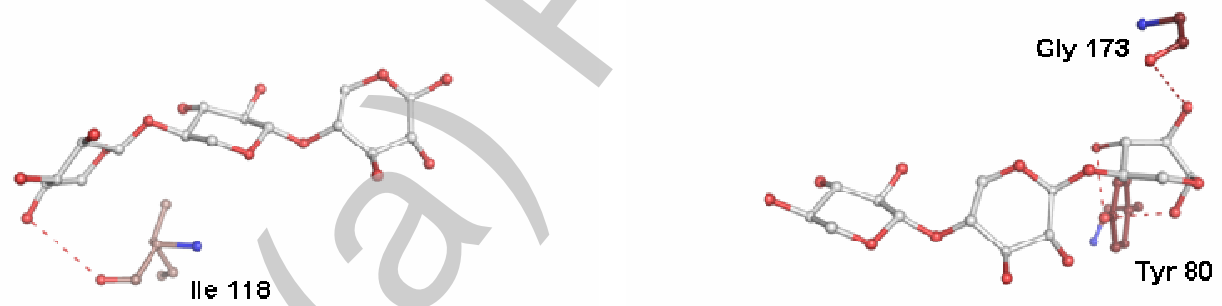


\section{Figure 3}

(a)

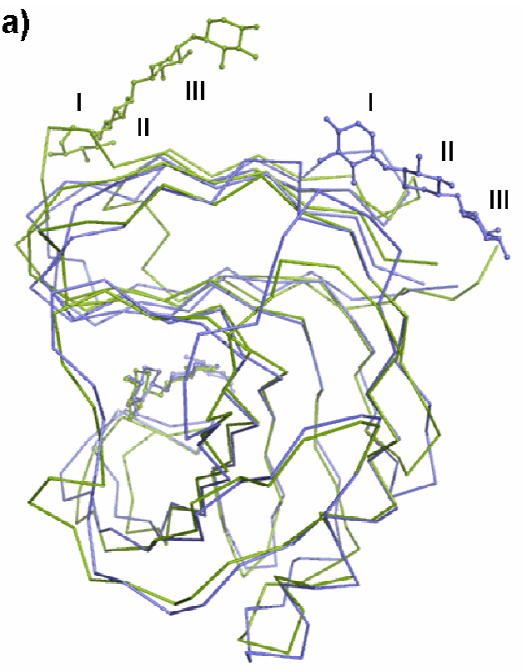

(b)

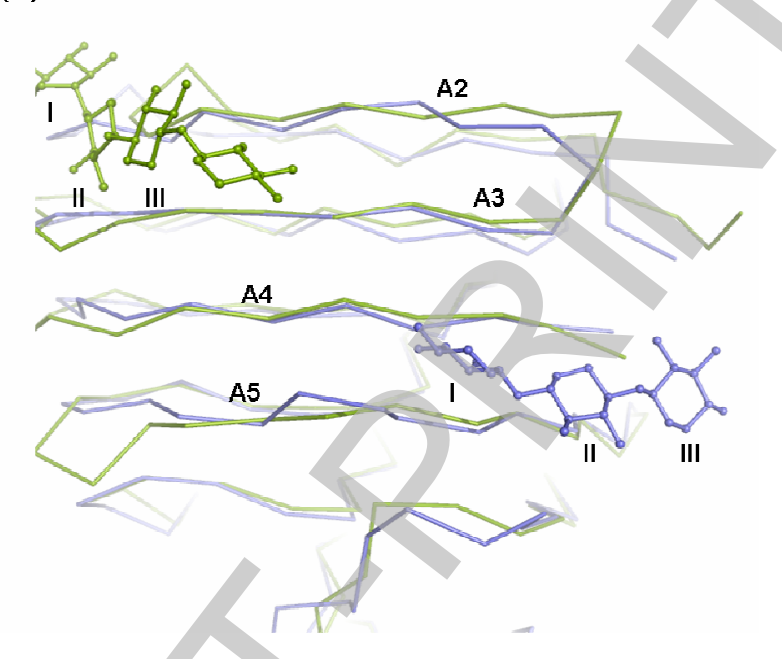




\section{Figure 4}

a)

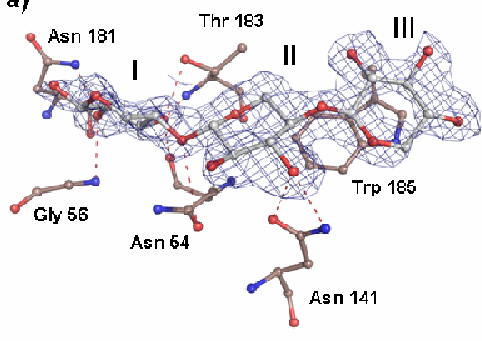

b)

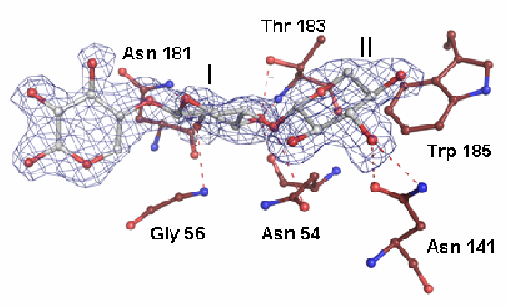

c) Asก 13

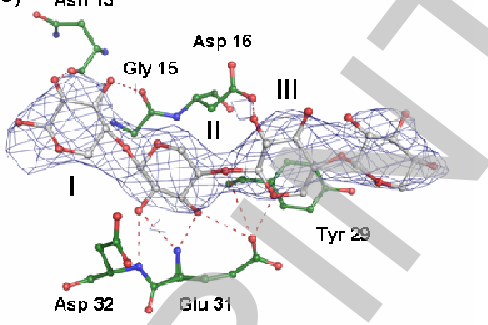

